\title{
Concentrations of Mineral in Amniotic Fluid and Their Relations to Selected Maternal and Fetal Parameters
}

\author{
J. Suliburska $^{1}$ - R. Kocyłowski ${ }^{2,3}$ - I. Komorowicz ${ }^{4}$ M. Grzesiak ${ }^{3}$ • P. Bogdański ${ }^{5}$. \\ D. Barałkiewicz ${ }^{4}$
}

Received: 8 August 2015 / Accepted: 25 October 2015 /Published online: 7 November 2015

(C) The Author(s) 2015. This article is published with open access at Springerlink.com

\begin{abstract}
The concentrations of various trace elements in amniotic fluid (AF) change over the course of pregnancy, with gestational age and fetus growth. The aim of the present study was to evaluate the concentrations of selected essential and toxic elements in AF and their relations to maternal and fetal parameters. The study was carried out in 39 pregnant women, aged $34.6 \pm 4.7$ years, between weeks 16 and 26 of gestation. Amniotic fluid samples were obtained during the standard procedure of amniocentesis in high-risk patients for chromosomal abnormalities. An inductively coupled plasma mass spectrometry (ICP-MS) technique was used to determine the levels of Al, As, Ba, Cd, Co, Cr, Cu, Mg, Mn, Ni, Sr, U, and V in AF. Body mass and blood pressure were measured in all the women. The basic parameters of fetal development were also assayed. It was found that the age of the mother, the gender of the fetus, and the week of the pregnancy may affect the concentrations of mineral in the amniotic fluid. Moreover, several significant correlations between the essential and toxic
\end{abstract}

J. Suliburska

jsulibur@up.poznan.pl

1 Department of Human Nutrition and Hygiene, Poznan University of Life Sciences, ul. Wojska Polskiego 31, 60-624 Poznan, Poland

2 PreMediCare New Med Medical Centre, ul. Drużbickiego 13, 61-693 Poznan, Poland

3 Department of Perinatology and Gynecology, Polish Mother's Memorial Hospital Research Institute, ul. Rzgowska 281/289, 93-338 Łódź, Poland

4 Department of Trace Element Analysis by Spectroscopy Method, Faculty of Chemistry, Adam Mickiewicz University in Poznań, ul. Umultowska 89b, 61-614 Poznan, Poland

5 Department of Education and Obesity Treatment and Metabolic Disorders, University of Medical Sciences, ul. Szamarzewskiego 84, 60-569 Poznan, Poland elements and maternal and fetal parameters were observed. In particular, negative and positive correlations between fetal parameters and magnesium and copper levels in AF, respectively, were seen. The present findings demonstrate the association between minerals in AF and fetal development.

Keywords Amniotic fluid $\cdot$ Minerals $\cdot$ Maternal factors $\cdot$ Fetal parameter

\section{Introduction}

During pregnancy, amniotic fluid (AF) surrounds the fetus and is circulated constantly by the baby's inhalation and exhalation, as well as swallowing and urination, of the fluid.

Maternal plasma - the source of the water in AF-passes through the fetal membranes under hydrostatic and osmotic forces. Through the vessels that develop in the placenta and fetus, water and solute from the maternal plasma pass across the placenta to the fetus and then to the AF. It can thus be assumed that the composition of AF reflects the composition of the fetal plasma [1]. The composition of AF depends on the mother's nutrition, including essential nutrients, and also on the mother's exposure to toxic substances. It has been found that proteins or peptides in the amniotic fluid possess potent bioactivity on cellular growth and proliferation and that they modulate the process of embryonic development [2].

The role of trace elements contained in AF is not clear. Because AF is swallowed by the fetus, it has been suggested that this fluid may be an important source of certain trace elements for fetal nutrition. AF is thus considered a valuable marker of prenatal mineral status and exposure to toxic metals.

Only a few investigations to date have evaluated the concentration of minerals in AF. Some studies have determined the essential elements levels in AF, and attempts have been 
made to establish normal values for the early weeks of pregnancy $[1,3]$. In other studies, it was demonstrated that heavy metals may accumulate in AF from a very early stage of gestation; however, little is known about the influence of metals in $\mathrm{AF}$ on fetal development or about the long-term effects of this early exposure [4].

However, there is a lack of standards and reference ranges for the concentrations of elements in AF by gestational age. It is not clear what factors determine the concentration of minerals in the AF. Little is known about the relationship between the concentration of elements in $\mathrm{AF}$ and fetal development. Accordingly, the aim of this study was to evaluate the concentration of selected essential and toxic elements in $\mathrm{AF}$ and their relations with maternal and fetal parameters.

\section{Material and Methods}

The study protocol was approved by the Bioethics Commission at Poznan University of Medical Sciences (approval no. 30/15). Informed consent was obtained from all women. The study was performed in accordance with Helsinki Declaration.

\section{Subjects}

The study was carried out on 39 pregnant women, aged $34.6 \pm$ 4.7 years. The mean gestational age was 20 weeks (range, 1626 weeks). The inclusion criteria were (1) intrauterine pregnancy, (2) pregnancy without congenital anomalies evaluated in ultrasound, (3) lack of signs and symptoms indicating risk of miscarriage (bleeding, pelvic pain, chorionic hematoma), and (4) informed consent. The exclusion criteria were (1) ectopic or heterotopic pregnancy, (2) multiple pregnancies, (3) positive obstetric history of multiple miscarriages, preterm birth, and fetal growth disorders (growth restriction, macrosomia), (4) observed birth defects or genetic conditions in the current pregnancy or present in the women, (5) use of drugs that affect the mineral balance in the organism, (6) diabetes, (7) infection, (8) gestational hypertension, and (9) maternal exposure to alcohol, cocaine, or tobacco smoke.

The full characteristics for the subjects are presented in Table 1. All subjects were informed of the study's aims, procedures, and measurement methods, and the individual consent of each patient was obtained.

\section{Maternal Parameters Measurements}

The body mass was calculated using the measurements of women wearing light clothing with bare feet. Weight was measured to the nearest $0.10 \mathrm{~kg}$ accuracy.
Table 1 Maternal and fetal parameters $(n=39)$

\begin{tabular}{llll}
\hline Parameters & $\begin{array}{l}\text { Mean } \pm \text { SD } \\
\text { Maternal } \\
\text { parameters }\end{array}$ & Median & Range (min-max) \\
\hline Sys (mmHg) & $125.1 \pm 12.5$ & 126 & $102-153$ \\
Dia (mmHg) & $73.4 \pm 7.8$ & 74 & $59-91$ \\
Body mass (kg) & $68.0 \pm 10.3$ & 66 & $50-90$ \\
Age (years) & $34.6 \pm 4.7$ & 34 & $24-42$ \\
Week of pregnancy & $20.3 \pm 3.0$ & 20.5 & $16-26$ \\
Fetal parameters & & & \\
FHR & $148.6 \pm 8.9$ & 150 & $135-178$ \\
UAPI & $1.41 \pm 0.48$ & 1.29 & $0.63-2.77$ \\
HC (mm) & $140.0 \pm 34.7$ & 132.5 & $90.9-213$ \\
AC (mm) & $120.4 \pm 29.7$ & 115.1 & $70.5-179$ \\
FL (mm) & $24.0 \pm 8.2$ & 20.9 & $12.2-41.0$ \\
EFW (g) & $232.8 \pm 134.5$ & 189.8 & $84.0-561.1$ \\
\hline
\end{tabular}

Sys systolic blood pressure, Dia diastolic blood pressure, FHR fetal heart rate, $U A P I$ umbilical artery pulsatility index, $B P D$ biparietal diameter, $A C$ abdominal circumference, $H C$ head circumference, $F L$ femur length, $E F W$ estimated fetal weight, $S D$ standard deviation

Resting arterial blood pressure was measured using regular adult cuffs. The measurements were obtained in a sitting position with the legs uncrossed and the back and arms supported. Blood pressure was measured three times, and an average value was calculated, according to the guidelines of the European Society of Hypertension [5].

\section{Measurement of Fetal Parameters}

Fetal parameters, such as fetal heart rate (FHR), umbilical artery pulsatility index (UAPI), biparietal diameter (BPD), abdominal circumference (AC), head circumference (HC), femur length (FL), and estimated fetal weight (EFW), were measured using ProSound Alpha7 (Aloka Co.) with convex 5-7 MHz probe. The fetal measurements followed the standard protocols for fetal biometry [6].

\section{Amniotic Fluid}

Amniotic fluid (AF) samples were obtained $(5 \mathrm{~mL})$ as a residue after genetic analysis as a result for amniocentesis. Samples were collected by transabdominal puncture using plastic syringes free of trace element contamination.

$\mathrm{AF}$ samples were centrifuged $(3000 \mathrm{rpm} / \mathrm{min}$ for $10 \mathrm{~min}$ at $4{ }^{\circ} \mathrm{C}$ ), frozen, and stored at $-80{ }^{\circ} \mathrm{C}$. 


\section{Measurement of Minerals in Amniotic Fluid}

\section{Sample Preparation}

After collection, amniotic fluid samples were immediately frozen and stored for analysis. Just prior to analysis, the samples were thawed and underwent digestion in a microwave oven model Ethos One (Milestone Srl, Italy). The samples for digestion were prepared as follows: $1 \mathrm{~mL}$ of the sample was transferred to the digestion vessels and $0.5 \mathrm{~mL}$ of $65 \%$ nitric acid (Merck, Germany) and $0.5 \mathrm{~mL}$ of $30 \%$ hydrogen peroxide (Fluka, Germany) were added to each vessel. The microwave oven heating program proceeded in steps: (1) ramp time of $20 \mathrm{~min}$ to reach $1500 \mathrm{~W}$, (2) hold time of $30 \mathrm{~min}$ at $1500 \mathrm{~W}$, and (3) cooling for $30 \mathrm{~min}$. The temperature during the digestion process was $180{ }^{\circ} \mathrm{C}$. The digested samples were quantitatively transferred into volumetric flasks, which had previously been prepared appropriately, first by soaking in $5 \%$ nitric acid for $24 \mathrm{~h}$ and then rinsed with deionized water. The digests were adjusted to $10 \mathrm{~mL}$ with deionized water (TKA Smart2Pure, Niederelbert, Germany). In parallel, the procedural blanks, including the same reagents as the samples, were prepared and digested in the same way as the samples in each digestion run.

\section{Analytical Procedure}

An Elan DRC II ICP-MS (PerkinElmerSCIEX, Ontario, Canada) was used to determine $\mathrm{Al}, \mathrm{As}, \mathrm{Ba}, \mathrm{Cd}, \mathrm{Co}, \mathrm{Cr}, \mathrm{Cu}$, $\mathrm{Mg}, \mathrm{Mn}, \mathrm{Ni}, \mathrm{Sr}, \mathrm{U}$, and $\mathrm{V}$ levels. A cyclonic spray chamber, a concentric glass nebulizer, and a quartz torch with a quartz injector were used. A quadrupole mass analyzer with goldcoated parallel rods was employed, as was an electron multiplier as the detector. Signal intensity was recorded as a counting signal or analog signal, each with its own detection range. The operating conditions for the inductively coupled plasma mass spectrometer (ICP-MS) were as follows: RF power was $1100 \mathrm{~W}$; plasma Ar flow rate was $15 \mathrm{~L} / \mathrm{min}$; nebulizer Ar flow rate was $0.86 \mathrm{~L} / \mathrm{min}$ and auxiliary Ar flow rate was $1.2 \mathrm{~L} / \mathrm{min}$; and lens voltage was 7.0-9.5 V. Argon with a purity of $99.999 \%$ was used as a nebulizer, auxiliary, and plasma gas (Linde Gaz, Poland). A mixed standard solution (Multielement Calibration Standard 3, Atomic Spectroscopy Standard, PerkinElmer Pure) containing analyzed elements at a concentration of $10 \mathrm{mg} \mathrm{L}^{-1}$ was used to construct calibration curves. The calibration curves for the elements were constructed in the range of 0.01 to $50 \mu \mathrm{g} \mathrm{L}^{-1}$. The isotopes of ${ }^{45} \mathrm{Sc},{ }^{74} \mathrm{Ge},{ }^{103} \mathrm{Rh}$, and ${ }^{159} \mathrm{~Tb}$ prepared from individual solutions with a concentration of $1000 \mathrm{mg} \mathrm{L}^{-1}$ were applied as internal standards in order to eliminate nonspectral interferences (ICP Standard CertiPUR, Merck, Germany). In turn, spectral interference was eliminated through the use of a dynamic reaction cell (DRC). As the DRC reaction gas, high- purity ammonia (99.999 \%) was used. Deionized water was used throughout the experiment [7].

\section{Figures of Merit and Analytical Performance}

After calibration, and also during the analysis, measurements were controlled by analysis of standard solutions at concentrations of 1 or $5 \mu \mathrm{g} \mathrm{L}^{-1}$ and certified reference materials after each batch of ten samples. Calibration curves for all elements proved to be linear over the whole concentration range, which resulted in good correlation coefficients of at least 0.999 . In order to ensure the reliability of the applied analytical procedure, analysis of the certified reference material is highly recommended. The accuracy of the method for the elements under investigation was evaluated by analyzing ten samples of the certified reference material of river water SLRS-5 and fortified lake water TM 27.3. The obtained values are presented in Table 2. Within day precision was calculated as the relative standard deviation and expressed in a percentage as the variation coefficient. The precision values for all the tested elements fell in the range from 1.2 to $22.2 \%$ for SLRS-5; however, for TM 27.3, the values were found to be in the 0.5-4.0 \% range. The limits of detection (LOD) were calculated as three standard deviations from the procedural blank samples. LOQ values were calculated as three times of the LOD values. LOD and LOQ values are gathered in Table 3.

\section{Statistical Analysis}

A detailed statistical analysis was performed with Statistica 10 for Windows. The normality of the variables' distribution was verified using the Shapiro-Wilk test. The Mann-Whitney $U$ test was used to compare differences between groups for all the studied parameters. Simple associations between parameters were calculated as the Spearman coefficient of correlation. The level of statistical significance was set to $p<0.05$.

\section{Results}

The mean, range, and median concentrations of the essential and toxic minerals in AF are shown in Table 4.

In this study, it was presumed that the factors most likely to influence the mineral concentrations in amniotic fluid are as follows: age of mothers, week of the pregnancy, and gender of the fetus.

It has been postulated that pregnancy in women over 35 years of age is associated with an increased risk of malformations. For this reason, subjects in this study were divided into two groups according to age: those less than 35 years old $(n=17)$ and those 35 years or older $(n=22)$. It was found that the concentration of magnesium was 
Table 2 Results of the measurements $(n=10)$ of certified reference materials: SLRS-5 and TM 27.3 given with certified values

\begin{tabular}{|c|c|c|c|c|c|c|}
\hline \multirow[t]{2}{*}{ Analyte } & \multicolumn{3}{|l|}{ River water SLRS-5 } & \multicolumn{3}{|l|}{ Fortified lake water TM 27.3} \\
\hline & Measured value $\left(\mu \mathrm{g} \mathrm{L}^{-1}\right)$ & Certified value $\left(\mu \mathrm{g} \mathrm{L}^{-1}\right)$ & Accuracy (\%) & Measured value $\left(\mu \mathrm{g} \mathrm{L}^{-1}\right)$ & Certified value $\left(\mu \mathrm{g} \mathrm{L}^{-1}\right)$ & Accuracy $(\%)$ \\
\hline $\mathrm{Al}$ & $46.84 \pm 0.65$ & $49.5 \pm 5.0$ & 95 & $42.8 \pm 1.7$ & $44.4 \pm 5.1$ & 96 \\
\hline As & $0.448 \pm 0.039$ & $0.413 \pm 0.039$ & 109 & $2.258 \pm 0.030$ & $2.15 \pm 0.30$ & 105 \\
\hline $\mathrm{Ba}$ & $14.6 \pm 1.3$ & $14.0 \pm 0.5$ & 104 & $15.96 \pm 0.21$ & $14.9 \pm 1.1$ & 107 \\
\hline $\mathrm{Cd}$ & $0.0095 \pm 0.0021$ & $0.0060 \pm 0.0014$ & 159 & $1.110 \pm 0.014$ & $1.05 \pm 0.12$ & 106 \\
\hline Co & $0.0607 \pm 0.0028$ & $0.05^{\mathrm{a}}$ & 121 & $1.888 \pm 0.020$ & $2.05 \pm 0.18$ & 92 \\
\hline $\mathrm{Cr}$ & $0.289 \pm 0.044$ & $0.208 \pm 0.023$ & 139 & $1.953 \pm 0.010$ & $1.73 \pm 0.33$ & 113 \\
\hline $\mathrm{Cu}$ & $17.07 \pm 0.54$ & $17.4 \pm 1.3$ & 98 & $6.01 \pm 0.12$ & $6.16 \pm 0.61$ & 98 \\
\hline $\mathrm{Mg}$ & $2752 \pm 46$ & $2540 \pm 160$ & 108 & - & - & - \\
\hline $\mathrm{Mn}$ & $4.12 \pm 0.32$ & $4.33 \pm 0.18$ & 95 & $2.232 \pm 0.016$ & $2.27 \pm 0.35$ & 98 \\
\hline $\mathrm{Ni}$ & $0.589 \pm 0.016$ & $0.476 \pm 0.064$ & 124 & $2.396 \pm 0.070$ & $2.44 \pm 0.53$ & 98 \\
\hline $\mathrm{Sr}$ & $52.40 \pm 0.65$ & $53.6 \pm 1.3$ & 98 & $98.4 \pm 1.4$ & $105 \pm 6$ & 94 \\
\hline $\mathrm{U}$ & $0.0908 \pm 0.0090$ & $0.093 \pm 0.006$ & 98 & $2.094 \pm 0.075$ & $2.03 \pm 0.19$ & 103 \\
\hline $\mathrm{V}$ & $0.360 \pm 0.049$ & $0.317 \pm 0.033$ & 114 & $2.170 \pm 0.042$ & $2.18 \pm 0.25$ & 100 \\
\hline
\end{tabular}

${ }^{\mathrm{a}}$ information value

significantly lower and that the levels of nickel, cadmium, barium, and chromium were markedly higher in the AF of older women (Table 5).

The samples were also divided into two different groups according to the gender of the fetus. A significant difference was found in the vanadium concentration in AF, with higher levels of vanadium shown in male fetuses than in female fetuses (Table 6).

The amniotic fluid samples were divided into two additional groups according to the week of pregnancy. The one of the group was between 16 and 20 week of gestation and the second group was between 21 and 26 week of gestation. The markedly higher concentration of copper and lower level of magnesium in the samples with longer period of pregnancy was observed (Table 7).

Table 3 LOD and LOQ
values

\begin{tabular}{lll}
\hline & LOD $\left(\mu \mathrm{g} \mathrm{L}^{-1}\right)$ & LOQ $\left(\mu \mathrm{g} \mathrm{L}^{-1}\right)$ \\
\hline $\mathrm{Al}$ & 6 & 18 \\
$\mathrm{As}$ & 0.04 & 0.12 \\
$\mathrm{Ba}$ & 0.25 & 0.75 \\
$\mathrm{Cd}$ & 0.004 & 0.012 \\
$\mathrm{Co}$ & 0.004 & 0.012 \\
$\mathrm{Cr}$ & 0.2 & 0.6 \\
$\mathrm{Cu}$ & 0.4 & 1.2 \\
$\mathrm{Mg}$ & 5 & 15 \\
$\mathrm{Mn}$ & 0.3 & 0.9 \\
$\mathrm{Ni}$ & 0.1 & 0.3 \\
$\mathrm{Sr}$ & 0.3 & 0.9 \\
$\mathrm{U}$ & 0.009 & 0.027 \\
$\mathrm{~V}$ & 0.04 & 0.12 \\
\hline
\end{tabular}

Table 8 shows the correlation between mineral concentrations in AF and selected maternal and fetal parameters. The maternal and fetal parameters are summarized in Table 1. Significant positive correlations between systolic blood pressure and the level of uranium and manganese in AF, and between diastolic blood pressure and the levels of nickel, strontium, cadmium, and manganese, were found. Moreover, a markedly negative correlation between the current body mass of women and the level of magnesium in AF was observed. Furthermore, there was a significant correlation between fetal parameters and magnesium and copper levels in AF. Significant positive correlations were seen between magnesium and umbilical artery pulsatility index (UAPI), copper and biparietal diameter (BPD), copper and abdominal circumference (AC), copper and head circumference (HC), copper and femur length (FL), and copper and estimated fetal weight (EFW) (Table 7). Moreover, markedly negative correlations between magnesium and BPD, HC, FL, and EFW were observed.

\section{Discussion}

The concentration of minerals in amniotic fluid was affected by maternal age, week of gestation, and gender of fetus. This is a novel finding of our study. We also showed that the level of minerals in AF correlates with some maternal and fetal parameters. To the best of our knowledge, this is the first study on pregnant women to demonstrate these relationships.

The range of concentration of some minerals in AF in this study - especially copper, strontium, cobalt, manganese, and barium - is in agreement with the results of other reports [1, 


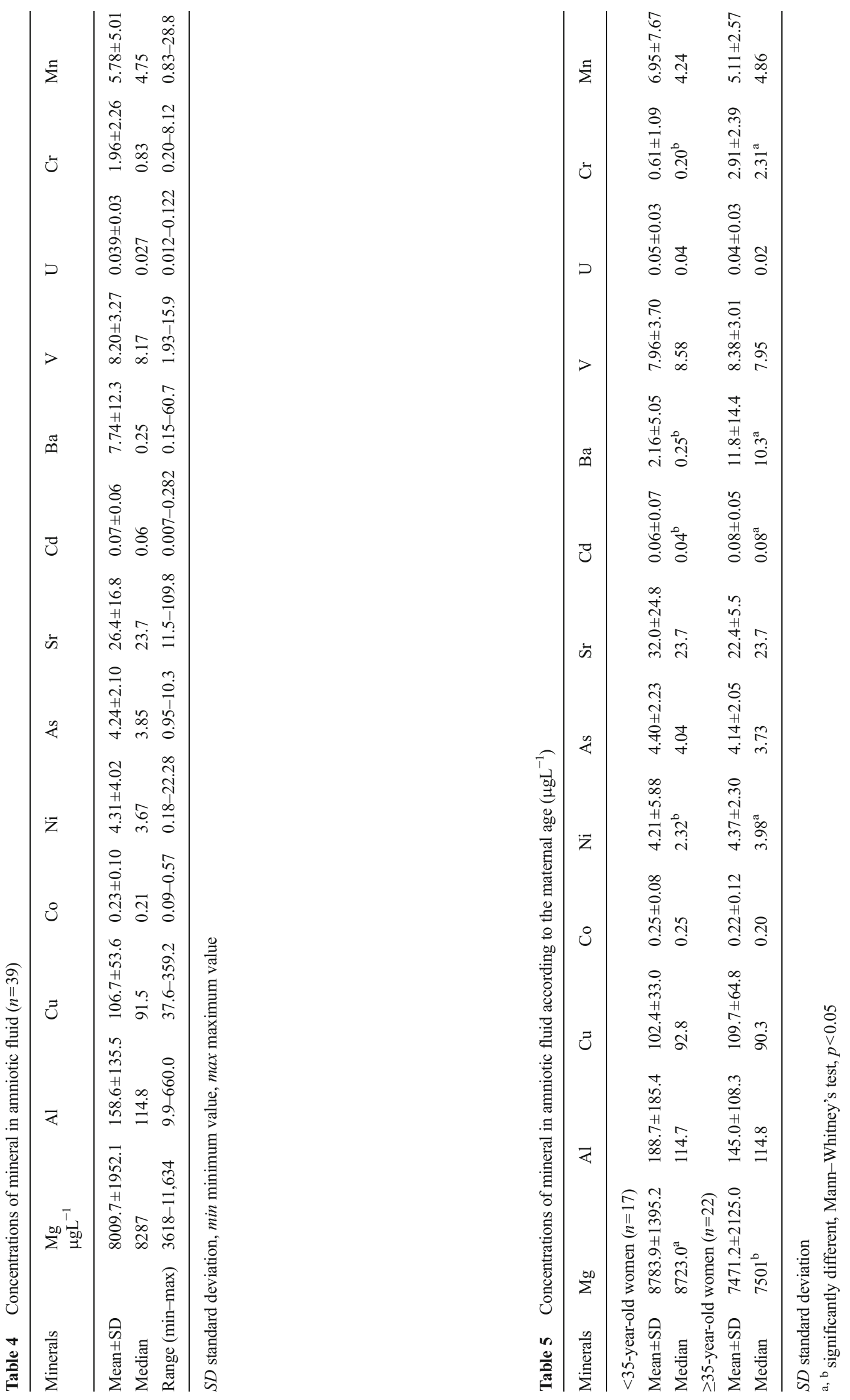




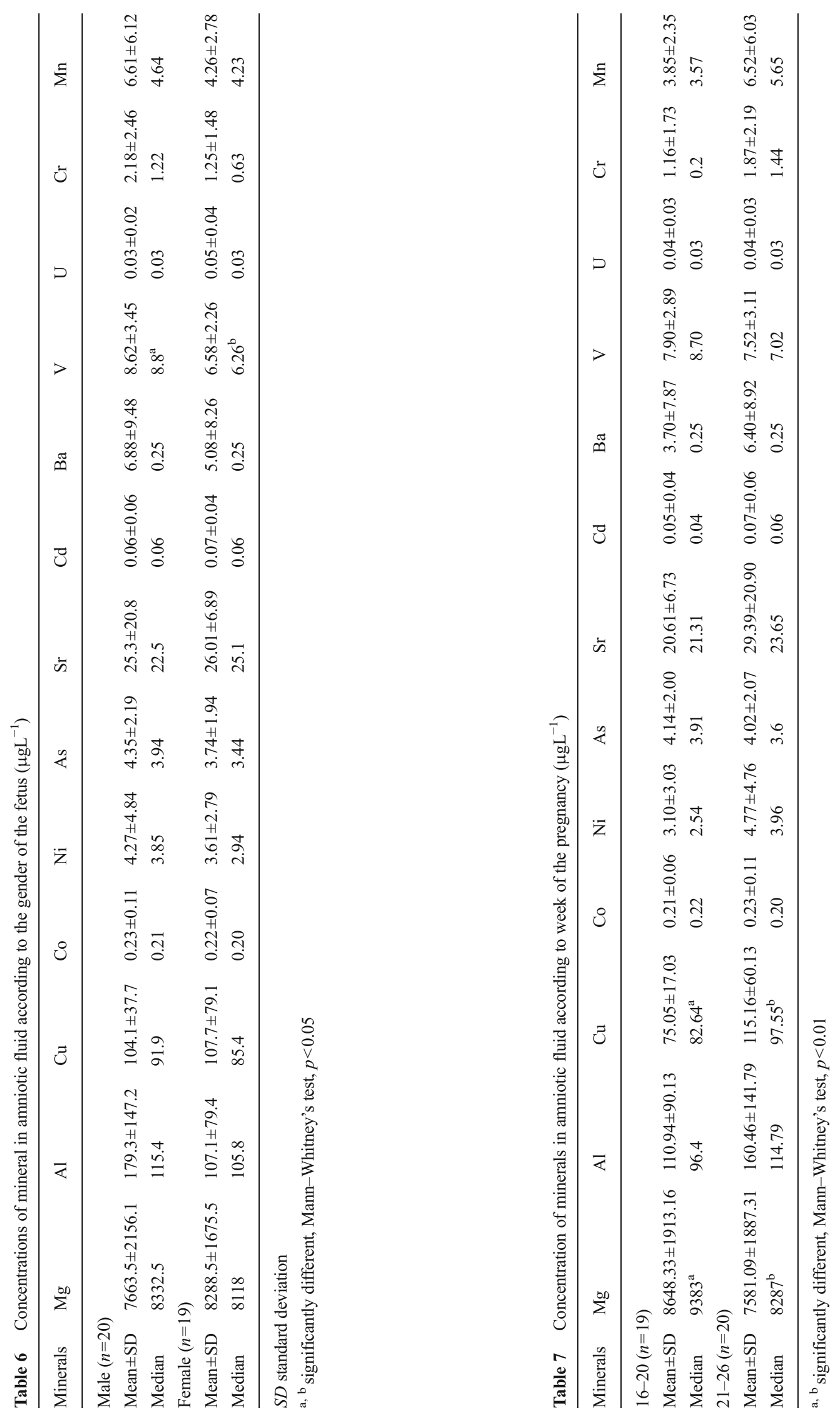


Table 8 Correlation between mineral levels in amniotic fluid and maternal and fetal parameters

\begin{tabular}{llllllllllllll}
\hline Parameters & $\mathrm{Mg}$ & $\mathrm{Al}$ & $\mathrm{Cu}$ & $\mathrm{Co}$ & $\mathrm{Ni}$ & $\mathrm{As}$ & $\mathrm{Sr}$ & $\mathrm{Cd}$ & $\mathrm{Ba}$ & $\mathrm{V}$ & $\mathrm{U}$ & $\mathrm{Cr}$ & $\mathrm{Mn}$ \\
\hline \multicolumn{2}{l}{ Maternal parameters } & & & & & & & & & & \\
Sys & -0.13 & 0.35 & 0.11 & 0.11 & 0.17 & 0.15 & 0.19 & 0.26 & 0.12 & 0.12 & $0.39^{*}$ & -0.01 & $0.45^{*}$ \\
Dia & -0.05 & 0.02 & -0.06 & 0.10 & $0.36^{*}$ & -0.10 & $0.35^{*}$ & $0.46^{*}$ & 0.00 & -0.11 & 0.15 & 0.14 & $0.37^{*}$ \\
Body mass & $-0.45^{*}$ & -0.04 & -0.02 & -0.25 & 0.07 & -0.29 & -0.31 & 0.06 & 0.29 & -0.31 & -0.21 & 0.15 & 0.04 \\
Fetal parameters & & & & & & & & & & & & & \\
FHR & 0.05 & -0.15 & 0.09 & -0.32 & 0.09 & 0.05 & -0.15 & -0.05 & -0.12 & 0.27 & -0.03 & 0.07 & 0.18 \\
UAPI & $0.40^{*}$ & 0.07 & -0.27 & -0.03 & -0.09 & 0.02 & 0.14 & 0.00 & -0.20 & -0.10 & 0.12 & -0.15 & -0.09 \\
BPD & $-0.39^{*}$ & 0.15 & $0.41^{*}$ & 0.15 & 0.16 & -0.08 & 0.12 & 0.27 & 0.29 & -0.08 & 0.09 & 0.25 & 0.20 \\
HC & $-0.38^{*}$ & 0.13 & $0.41^{*}$ & 0.14 & 0.15 & -0.11 & 0.12 & 0.25 & 0.30 & -0.12 & 0.11 & 0.24 & 0.16 \\
AC & -0.27 & 0.09 & $0.40^{*}$ & 0.15 & 0.11 & -0.08 & 0.11 & 0.21 & 0.19 & -0.08 & 0.02 & 0.16 & 0.14 \\
FL & $-0.40^{*}$ & 0.14 & $0.41^{*}$ & 0.14 & 0.22 & -0.12 & 0.15 & 0.29 & 0.28 & -0.13 & 0.03 & 0.27 & 0.25 \\
EFW & $-0.34^{*}$ & 0.12 & $0.41^{*}$ & 0.13 & 0.17 & -0.09 & 0.11 & 0.25 & 0.22 & -0.09 & 0.00 & 0.24 & 0.20 \\
\hline
\end{tabular}

Sys systolic blood pressure, Dia diastolic blood pressure, $F H R$ fetal heart rate, UAPI umbilical artery pulsatility index, $B P D$ biparietal diameter, $A C$ abdominal circumference, $H C$ head circumference, $F L$ femur length, $E F W$ estimated fetal weight

* Spearman correlation $(R), p<0.05$

4]. However, some other authors have observed lower levels of aluminum, copper, nickel, strontium, and vanadium and higher levels of barium and magnesium in amniotic fluid than in this study $[2,4,8]$. There are several factors that may affect the differences in the results obtained in various studies, such as age of the mother, week of pregnancy, and the analytical methods used. In this study, it was found that the concentration of metals such as nickel, cadmium, and barium increased in AF with maternal age. It is possible that, in older mothers, the period of exposure to metals was longer, and hence, the accumulation of these minerals in the body of the mothers and their passage into the AF was greater [9]. Higher concentrations of metal in AF may suggest increased risks of abnormal fetal development, because the fetus inhales and swallows amniotic fluid at a turnover rate of one third of its volume every hour [8]. In this study, it was observed that lower levels of magnesium were found in the amniotic fluid of older mothers. Low magnesium levels in AF are associated with complications of pregnancy such as preeclampsia and diabetes [3], and it is known that women with advanced maternal age are at high risk of developing these diseases [10-12]. Moreover, the concentration of some minerals (including magnesium) in women's bodies may depend on age. It was found that the concentration of magnesium in the hair of women of reproductive age was significantly lower in subjects in the 31-40 age range than in younger or older subjects [13].

In the later weeks of gestation, the concentration of copper in AF was significantly higher. This may be caused by longer time of maternal exposure to this element from food, water, and environment, and the increased secretion of copper in fetal urine. It is known that the absorption of copper rises during pregnancy due to the increasing need for maternal coppercontaining enzymes, and copper is also critical in fetal development [1]. In this study, we observed the positive correlations between copper concentration in $\mathrm{AF}$ and fetal biometric parameters. Similar concentrations of copper in the AF of women of similar age and in similar weeks of pregnancy have been reported by other authors [14]. The increase in the level of copper and other minerals in AF as pregnancy progressed was also observed in experimental models in pigs [15]. Because AF is swallowed by the fetus, Richards [15] suggested that this fluid may be an important source of copper for fetal nutrition. Increases in copper concentration in AF may reflect an increasing level of this mineral in the mother's blood during pregnancy [16]. It was found that the concentration of trace elements in AF linearly correlates with maternal serum [16]. Other authors have found that zinc in human $\mathrm{AF}$ increases during pregnancy and that the most significant period for this rise is the third trimester [17].

In this study, the concentration of magnesium was lower in the samples of amniotic fluid with longer gestational age in the second trimester. These results were confirmed by the study of Facchinetti et al. [18]. It is known that magnesium plays an important role in pregnancy and fetal development. The fall in levels of magnesium over the course of pregnancy can attest to the fact that this essential mineral is used for building the body and metabolism in the fetus. This finding is very important, because magnesium deficiency may be a major factor of pathogenesis in complicated pregnancies and also may cause metabolic problems extending into adult life [19, 20].

In several studies, fetal gender was seen to relate to the concentration of some AF components, such as cytokines, hormones, and minerals [21-23]. Tzschoppe et al. [23] found significantly higher concentrations of potassium, magnesium, and phosphate in the AF of male fetuses. In this study, higher levels of vanadium were seen in the amniotic fluid of male 
fetuses than of female fetuses. These results may point to sexspecific differences in physiological or hormonal changes in fetuses. Confirmation of such differences is provided by one study that showed that male fetal gender is associated with higher levels of proinflammatory cytokines and angiogenic factors in the mother's blood than female fetal gender [24]. It is known that vanadium is a factor associated with the process of angiogenesis [25], and this may also partly explain the present study's results.

It was found that high blood pressure in mothers correlated with higher concentration of nickel, strontium, cadmium, uranium, and manganese in AF. Relationships between the levels of these metals and high blood pressure in different populations (including in pregnant women) have been demonstrated in several studies [26-30]. Since amniotic fluid is swallowed by the fetus, higher levels of metals in this fluid may lead to an increased risk of hypertension in the child.

The significant correlations that were observed between minerals in the AF and the fetal parameters are partially confirmed by the results for gestational age (Tables 7 and 8). As pregnancy proceeded, the concentration of copper in AF increased and magnesium concentration decreased. Moreover, fetal growth parameters such as BPD, AC, HC, FL, and EFW are negatively correlated with the concentration of magnesium and positively correlated with the level of copper in the AF.

In this study, a significant positive correlation was found between the magnesium level in AF and umbilical artery pulsatility index (UAPI). The association between these parameters was also demonstrated in other studies [31-33]. Moreover, it was observed that the UAPI value, like the magnesium concentration, decreases with gestational age $[18,31]$.

This study has some limitations. In particular, the size of the group was small, and so this research is rather a pilot study. Due to the small group size, we could not attempt to establish reference values for the concentrations of minerals in the amniotic fluid at given gestational ages. We analyzed only certain minerals in the amniotic fluid, but not in the mother's blood or in the umbilical cord blood, which would allow broader conclusions about the association between mineral status and fetal development. Moreover, the daily intake and eating habits of the mothers' were not included in this study, and therefore, it was not possible to determine the influence of mothers' diet on minerals concentration in the amniotic fluid samples.

In conclusion, our results suggest a relationship between mineral level in AF and fetal development. These findings can present an additional opportunity for diagnosing fetal development. Further investigations with a larger group of pregnant women is needed to explain the mechanism of this association and to determine of the reference values for mineral levels in the amniotic fluid at various stages of pregnancy.

\section{Compliance with Ethical Standards}

Conflict of Interest The authors declare that they have no competing interests.

Ethics Approval and Consent to Participate The study protocol was approved by the Bioethics Commission at Poznan University of Medical Sciences (approval no. 30/15). Informed consent was obtained from all women. The study was performed in accordance with Helsinki Declaration.

Open Access This article is distributed under the terms of the Creative Commons Attribution 4.0 International License (http:// creativecommons.org/licenses/by/4.0/), which permits unrestricted use, distribution, and reproduction in any medium, provided you give appropriate credit to the original author(s) and the source, provide a link to the Creative Commons license, and indicate if changes were made.

\section{References}

1. Silberstein T, Saphier M, Mashiach Y, Paz-Tal O, Saphier O (2015) Elements in maternal blood and amniotic fluid determined by ICPMS. J Matern Fetal Neonatal Med 28(1):88-92

2. Tong XL, Wang L, Gao TB, Qin YG, Qi YQ, Xu YP (2009) Potential function of amniotic fluid in fetal development - novel insights by comparing the composition of human amniotic fluid with umbilical cord and maternal serum at mid and late gestation. J Chin Med Assoc 72(7):368-373

3. Bocos Terraz JP, Izquierdo Álvarez S, Bancalero Flores JL, González López A, Escanero Marcén JF (2011) Magnesium concentration in amniotic fluid in the early weeks of the second trimester of pregnancy. BMC Research Notes 4:185-188

4. Caserta D, Mantovani A, Ciardo F, Fazi A, Baldi M, Sessa MT, la Rocca C, Ronchi A, Moscarini M, Minoia C (2011) Heavy metals in human amniotic fluid: a pilot study. Prenat Diagn 31(8):792-796

5. Mancia G, Laurent S, Agabiti-Rosei E, Ambrosioni E, Burnier M, Caulfield MJ (2009) Reappraisal of European guidelines on hypertension management: a European Society of Hypertension Task Force document. J Hypertens 27:2121-2158

6. Bakalis S, Silva M, Akolekar R, Poon LC, Nicolaides KH (2015) Prediction of small-for-gestational-age neonates: screening by fetal biometry at 30-34 weeks. Ultrasound Obstet Gynecol 45(5):551558

7. Komorowicz I, Gramowska H, Barałkiewicz D (2010) Estimation of the lake water pollution by determination of 18 elements using ICP-MS method and their statistical analysis. J Environ Sci Health A Tox Hazard Subst Environ Eng 45(3):348-354

8. Hall GS, Carr MJ, Cummings E, Lee M (1983) Strontium in amniotic fluid by emission spectrometry. Clin Chem 29(6):1318

9. Edwards SE, Maxson P, Miranda ML, Fry RC (2015) Cadmium levels in a North Carolina cohort: identifying risk factors for elevated levels during pregnancy. J Expo Sci Environ Epidemiol 25: $427-432$

10. Lamminpaa R, Vehviläinen-Julkunen K, Gissler M, Heinonen S (2012) Preeclampsia complicated by advanced maternal age: a registry-based study on primiparous women in Finland 19972008. BMC Pregnancy Childbirth 12:47. doi:10.1186/1471-2393$12-47$ 
11. Jolly M, Sebire N, Harris J, Robinson S, Regan L (2000) The risks associated with pregnancy in women aged 35 years or older. Hum Reprod 15(11):2433-2437

12. Traisrisilp K, Tongsong T (2015) Pregnancy outcomes of mothers with very advanced maternal age (40 years or more). J Med Assoc Thai 98(2):117-122

13. Suliburska J (2011) A comparison of levels of select minerals in scalp hair samples with estimated dietary intakes of these minerals in women of reproductive age. Biol Trace Elem Res 144(1-3):7785

14. Weekes EW, Tamura T, Davis RO, Birch R, Vaughn WH, Franklin JC, Barganier C, Cosper P, Finley SC, Finley WH (1992) Nutrient levels in amniotic fluid from women with normal and neural tube defect pregnancies. Biol Neonate 61(4):226-231

15. Richards MP (1999) Zinc, copper, and iron metabolism during porcine fetal development. Biol Trace Elem Res 69(1):27-44

16. Tabrizi FM1, Pakdel FG2 (2014) Serum level of some minerals during three trimesters of pregnancy in iranian women and their newborns: a longitudinal study. Indian J Clin Biochem 29(2):174 180

17. Ozdamar O, Gün I, Müngen E, Atay V (2014) The assessment of the relationship between amniotic fluid matrix metalloproteinase-9 and zinc levels with adverse obstetric outcomes. Arch Gynecol Obstet 290(1):59-64

18. Facchinetti F, Borella P, Valentini M, Segre A, Battaglia C, Genazzani AR (1989) Intra-uterine growth retardation is associated with increased levels of magnesium in amniotic fluid. Eur J Obstet Gynecol Reprod Biol 32(3):227-232

19. James MF (2010) Magnesium in obstetrics. Best Pract Res Clin Obstet Gynaecol 24(3):327-337

20. Rylander R (2015) Pregnancy and magnesium. Pregnancy Hypertens 5(1):151

21. Weissenbacher T, Laubender RP, Witkin SS, Gingelmaier A, Schiessl B, Kainer F, Friese K, Jeschke U, Dian D, Karl K (2012) Influence of maternal age, gestational age and fetal gender on expression of immune mediators in amniotic fluid. BMC Res Notes 24(5):375-382

22. Mittal P, Hassan SS, Espinoza J, Kusanovic JP, Edwin S, Gotsch F, Erez O, Than NG, Mazaki-Tovi S, Romero R (2008) The effect of gestational age and labor on placental growth hormone in amniotic fluid. Growth Horm IGF Res 18(2):174-179

23. Tzschoppe A, Rauh M, Goecke TW, Yazdi B, Hart N, Siemer J, Schild RL, Dötsch J (2012) Sex-specific differences in the concentration of tubular parameters in the amniotic fluid of second trimester fetuses. Prenat Diagn 32(5):476-479

24. Enninga EA, Nevala WK, Creedon DJ, Markovic SN, Holtan SG (2015) Fetal sex-based differences in maternal hormones, angiogenic factors, and immune mediators during pregnancy and the postpartum period. Am J Reprod Immunol 73(3):251-262

25. Paglia DN, Wey A, Park AG, Breitbart EA, Mehta SK, Bogden JD, Kemp FW, Benevenia J, O'Connor JP, Lin SS (2012) The effects of local vanadium treatment on angiogenesis and chondrogenesis during fracture healing. J Orthop Res 30(12):1971-1978

26. Almenara CC, Broseghini-Filho GB, Vescovi MV, Angeli JK, Faria Tde O, Stefanon I, Vassallo DV, Padilha AS (2013) Chronic cadmium treatment promotes oxidative stress and endothelial damage in isolated rat aorta. PLoS One 8(7), e68418

27. Kosanovic M, Jokanovic M, Jevremovic M, Dobric S, Bokonjic D (2002) Maternal and fetal cadmium and selenium status in normotensive and hypertensive pregnancy. Biol Trace Elem Res 89(2): $97-103$

28. Mordukhovich I, Wright $\mathrm{RO}, \mathrm{Hu} \mathrm{H}$, Amarasiriwardena $\mathrm{C}$, Baccarelli A, Litonjua A, Sparrow D, Vokonas P, Schwartz J (2012) Associations of toenail arsenic, cadmium, mercury, manganese, and lead with blood pressure in the normative aging study. Environ Health Perspect 120(1):98-104

29. Shiue I (2014) Higher urinary heavy metal, arsenic, and phthalate concentrations in people with high blood pressure: US NHANES, 2009-2010. AbstractSend to:Blood Press 23(6):363-369

30. Wang SJ, Paek DM, Kim RH, Cha BS (2002) Variation of systolic blood pressure in rats exposed to cadmium and nickel. Environ Res 88(2):116-119

31. Chang CP, Wang HI, Wang PH, Yang MJ, Chang CM, Juang CM, Chen YJ, Horng HC, Tseng JY, Yen MS, Chen CY, Chao KC (2014) Umbilical artery Doppler velocimetry in normal pregnancies from $11(+0)$ to $13(+6)$ gestational weeks: a Taiwanese study. Taiwan J Obstet Gynecol 53(2):193-196

32. Dasgupta S, Ghosh D, Seal SL, Kamilya G, Karmakar M, Saha D (2012) Randomized controlled study comparing effect of magnesium sulfate with placebo on fetal umbilical artery and middle cerebral artery blood flow in mild preeclampsia at $\geq 34$ weeks gestational age. J Obstet Gynaecol Res 38(5):763-771

33. Farshchian N1, Rezavand N, Mohammadi S (2012) Effect of magnesium sulfate on Doppler parameters of fetal umbilical and middle cerebral arteries in women with severe preeclampsia. J Clin Imaging Sci 2:85 